\title{
Study of the Influence of Chemical Treatment on the Performances of the Mechanical Properties of the Naturel Fibre of Agave Americana Marginata
}

\author{
Hamza DJIZI \\ Université de Skikda, Algeria, hamzaschiffer@gmail.com \\ Azzedine BOUZAOUIT \\ Université de Skikda, Algeria, bouzaouit21@gmail.com
}

\begin{abstract}
Today the use of plant fibers in industrial fields and especially in composite materials appears as a good alternative and it has become widespread due to the interest of these fibers and their physical, biological and economic properties. So for that, composites or bio-composites are fairly developed materials and well involved in the industry. Our research has focused on the characterization of new fibers behavior and understanding their mechanical behavior regarding chemicals treatments to build better bio-composites. In this context, we are studying the fibers of Agave Americana Marginata, which is a widespread plant in Algeria with yellow and green leaves up to a length of two meters but it is not yet exploited. The first step that has been made is the extraction of the fibers by a simple ecological method is to immerse the cut leaves in a barrel of water closed at a temperature of about $30^{\circ}$ for 25 days so that we can extract and treat these fibers with three chemicals: $\mathrm{NaOH}_{1} \mathrm{KMnO}_{4}$ and $\mathrm{Na}_{2} \mathrm{CO}_{3}$. In each product nine bundles of fibers are considered as samples, each bundle contains 50 fibers for tensile tests. These sheaves are treated at room temperature with different durations and for several concentrations. After the treatments, a microscope observed these fibers and the results show the perfect elimination of the porosity and the increase of the roughness of the fibers, which constitutes an important advantage for us because the mechanical properties of the composites will be improved. In addition, these fibers are subjected to tensile tests to observe the effect of the three chemical treatments on their properties.
\end{abstract}

Keywords

natural fibers, chemical treatments, mechanical properties, bio-composites, agave

\section{Introduction}

Natural fibers are the best alternatives to synthetic fibers (synthetic fiber is a fiber produced from synthetic materials, which are obtained by synthesis of chemical compounds or comes exclusively from hydrocarbons or more recently from starch [1].

Previously researchers are studying this plant (agave) because these fibers have unique characteristics and the most important thing is the protection of the environment because they are biodegradable $[2,3]$.

In this article, continuing the research already done in this field $[4,5]$, we study the behavior of agave Americana Marginata fibers, carrying out treatments with different chemicals $\left(\mathrm{NaOH}, \mathrm{KMnO}_{4}, \mathrm{Na}_{2} \mathrm{CO}_{3}\right)$ in order to improve some characteristics mechanical properties of these fibers.

Bio-composite is a composite material formed by two essential components, the matrix, which is the resin, and the reinforcement, which is the natural fibers [6]. These materials mimic the structure of living materials involved in the process by retaining the reinforcing properties of the matrix used. The matrix is important to protect the fibers from environmental degradation and mechanical damage and to keep the fibers together. In addition, bio-fibers are the main components of bio-composites that come from biological origin, for example, the American agave fibers 'Marginata' that is the plant of our research in this article [7].

Agave Americana is a succulent plant and belongs to the family Agavaceae. It is located in North or Central America. It can be found in a large region, especially in America and Africa.

The Agave Americana "Marginata" is a plant that can be considered a shrub. Its leaves have yellow and green colors and grow up to $2 \mathrm{~m}$ or more in height, and 2 to $3 \mathrm{~m}$ wide. It produces a rosette of succulent and banded basal leaves, 15 to $20 \mathrm{~cm}$ wide and 1 to $2 \mathrm{~m}$ long, margined by spines and with a sharp apical tip [8]. 
Agave fibers are fibers that have good tensile strength and some stretch. Light-colored, lustrous, these fibers measure up to $280 \mathrm{~cm}$ long for a fable diameter. The textile material extracted from these fibers is called "pite" [3, 9].

Our work consists of the following steps (Figure 1): fiber extraction, treatment chemical, measuring fiber diameter and tensile test.

For extracting agave fibers we use simple methods such as using a sharp tool to scrape the outer layer and applied mechanical threshing to get the fibers. However, in this research another method is used, the leaves were immersed in a barrel of water for 15 to 20 days to separate the pectins and hemicelluloses. We call this step pre-treatment [10].

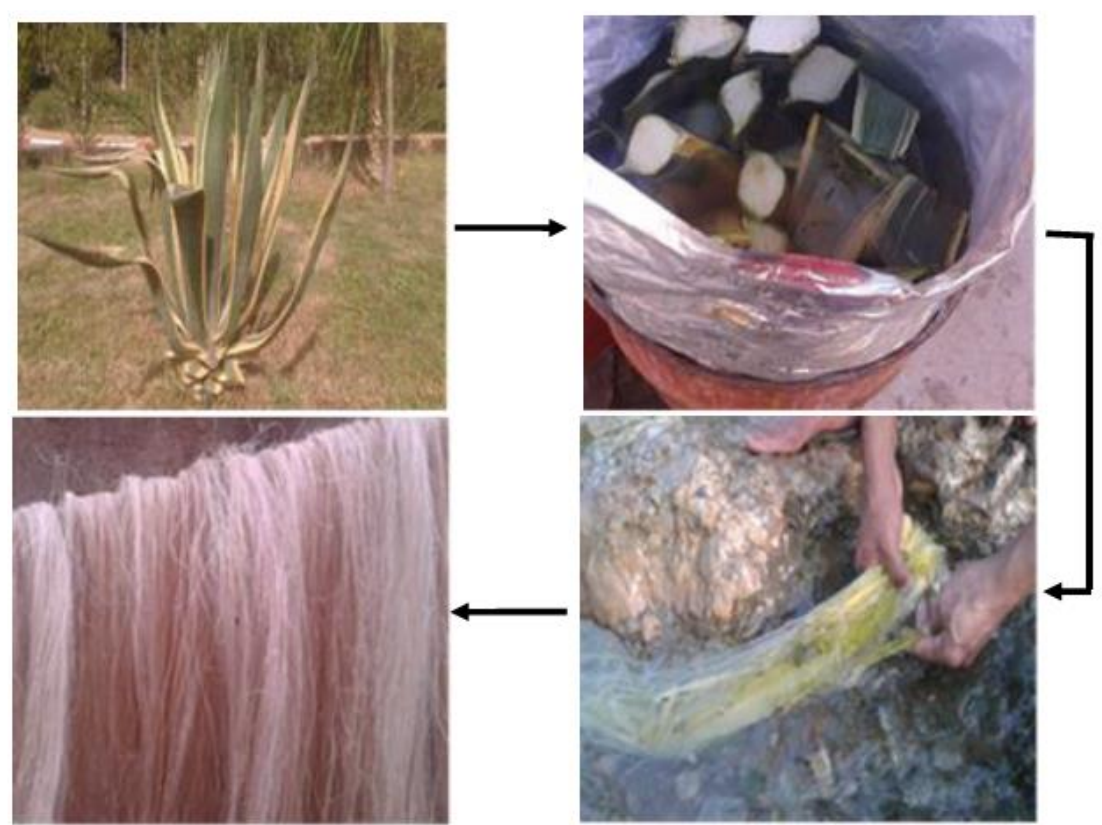

Fig. 1. Steps to extract Agave fibers

\section{Chemical Treatment}

After the extraction of Agave fibers, the chemical treatments are carried out with 3 products $\left(\mathrm{KMnO}_{4}\right.$, $\mathrm{NaOH}, \mathrm{Na}_{2} \mathrm{CO}_{3}$ ), at room temperature with different durations and for several concentrations. This treatment aims to improve their thermo-physicochemical and mechanical properties, to have a good fiber/matrix adhesion.

\section{1. $\mathrm{NaOH}$ treatment}

Sodium hydroxide $(\mathrm{NaOH})$, also known as caustic soda, is a strong base that occurs at room temperature in solid form. It consists of sodium $\left(\mathrm{Na}^{+}\right)$and hydroxide $\left(\mathrm{OH}^{-}\right)$anions. It is very soluble in water. Its aqueous solution is transparent and often called soda. Concentrated, it is, like sodium hydroxide in the solid state, particularly corrosive [11].

We have nine types of fiber samples each type contains 50 samples. These samples are treated with $\mathrm{NaOH}$ at room temperature with different durations (2, 6 and 12 hours) and for several concentrations $(0.5,1.5$ and $3 \%)$, as shown in the Figure 2.

\section{2. $\mathrm{KMnO}_{4}$ treatment}

Potassium permanganate $\left(\mathrm{KMnO}_{4}\right)$ is a particularly powerful oxidant. It is in the form of purple crystals composed of potassium ions, $\mathrm{K}^{+}$, and permanganate ions, $\left[\mathrm{MnO}_{4}\right]$. It is odorless and its taste is bitter [12].

We have nine types of fiber samples each type contains 50 samples. These samples are treated with $\mathrm{KMnO}_{4}$ at room temperature with different durations $(2,6$ and 10 minutes) and for several concentrations $(0.03,0.075$ and $0.125 \%)$, the treatment is presented by Figure 3. 


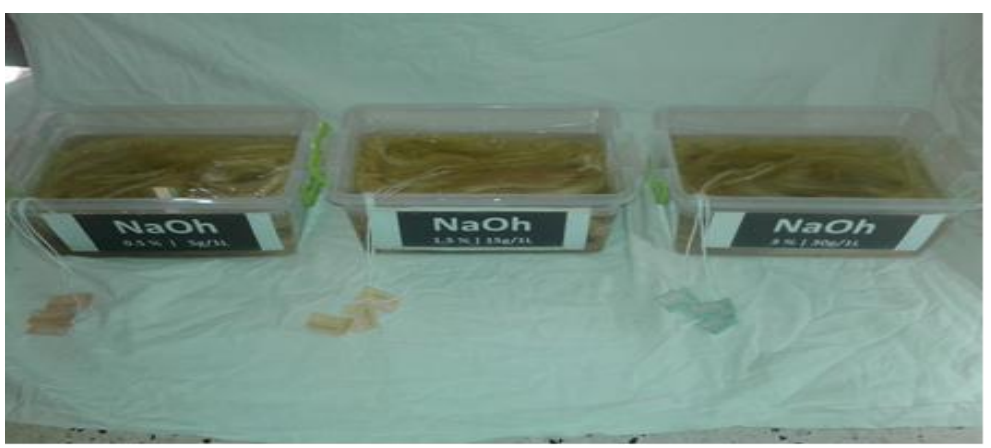

Fig. 2. NaOH treatment

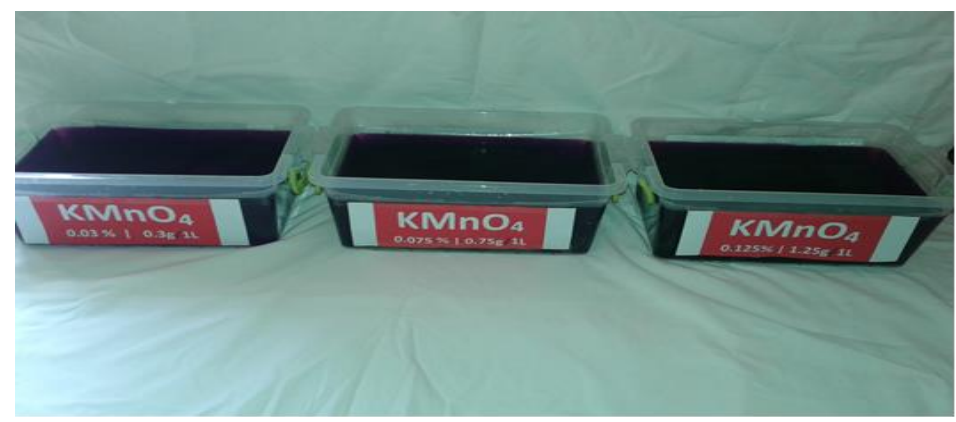

Fig. 3. $\mathrm{KMnO}_{4}$ treatment

\section{3. $\mathrm{Na}_{2} \mathrm{Co}_{3}$ treatment}

Sodium carbonate is a mineral chemical compound having the formula $\mathrm{Na}_{2} \mathrm{CO}_{3}$ and corresponding to the natural mineral species called natrite. It is a sodium salt of carbonic acid, it is one of the great versatile products of modern chemistry. In common parlance, this ionic solid, most often in powdery form, and its aqueous solutions are respectively called soda and soda crystals, the common name of this ancient mineral alkali, used early in the ancient glass industry [13].

We have nine types of fiber samples each type contains 50 samples. These samples are treated with $\mathrm{Na}_{2} \mathrm{CO}_{3}$ at room temperature with different durations $(7,10$ and 15 days) and for several concentrations (5, 10 and 15\%), as presented on Figure 4.

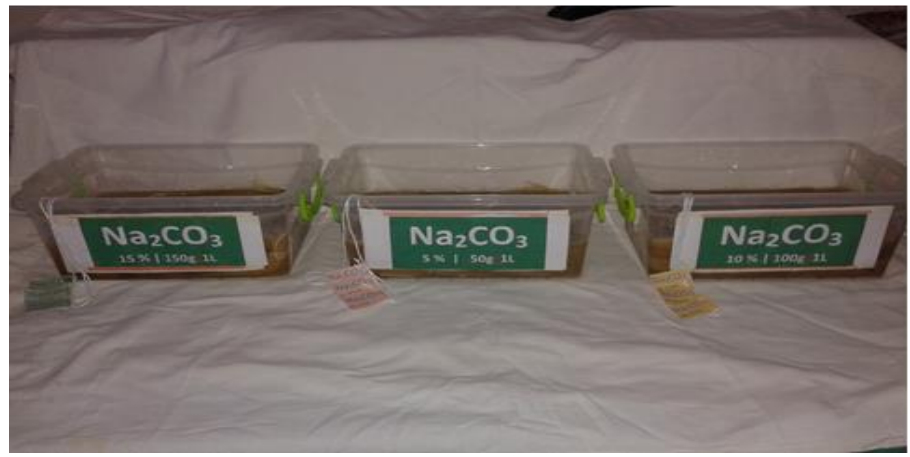

Fig. 4. $\mathrm{Na}_{2} \mathrm{CO}_{3}$ treatment

\section{Measuring fiber diameter and tensile tests}

After the chemical treatment, we try to measure the diameter of each fiber, a microscope connected to the computer is used and six measurements of each fiber are made to obtain the average diameter of the fiber.

The tensile tests were carried out with samples of the treated fibers, each sample having a length ( $\mathrm{L}=80 \mathrm{~mm}$ ) on an MTS machine model $4 \mathrm{~S}$, as shown in (Fig.6). The samples were tested at room temperature at a displacement speed of $10 \mathrm{~mm} / \mathrm{min}$. The tensile properties (modulus of elasticity (E), stress $\sigma$, strain $\varepsilon$ ) are evaluated from tables and curves. 


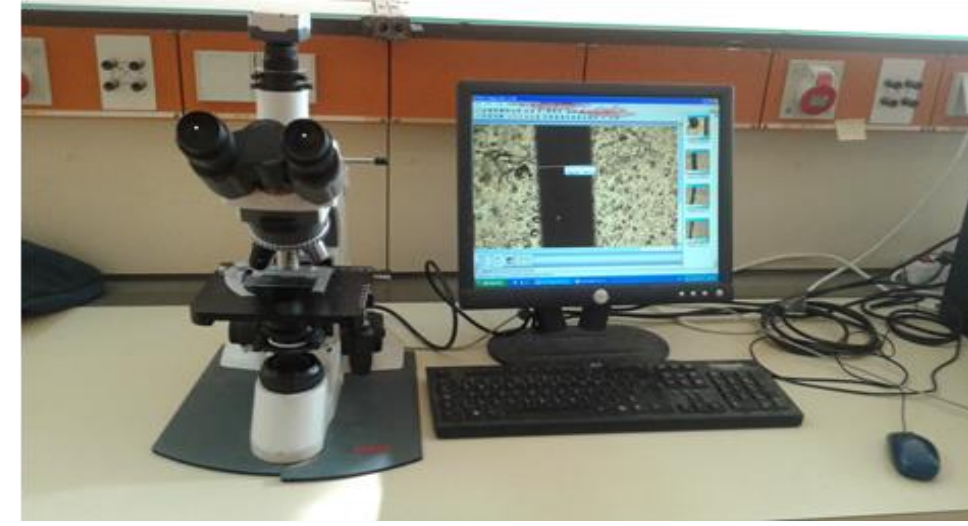

Fig. 5. Measuring microscope

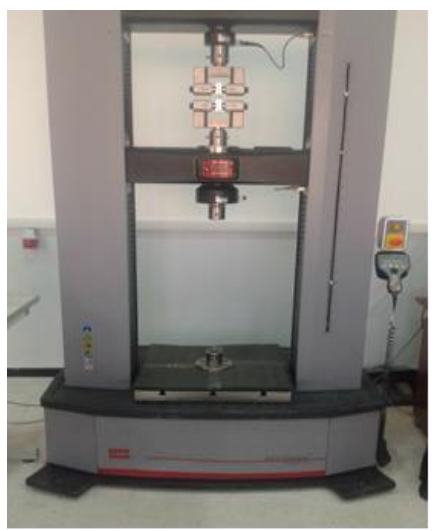

Fig. 6. MTS machine model $4 \mathrm{~S}$

\section{Results and discussion}

After treating the fibers with chemicals and after the tensile experiments, the results are presented by the Figures 7, 8, and 9. With these results, we found that the treatment of plant fibers with different chemical solutions has a considerable impact on the mechanical properties of fibers. The duration of each treatment also played an important role.

From Figure 7, it is clearly seen that the property of deformation at break is better if $\mathrm{KMnO}_{4}$ is used with a concentration of $0.125 \mathrm{~g}$ as a treatment solution, the strain stress increases considerably just after 6 minutes of treatment.
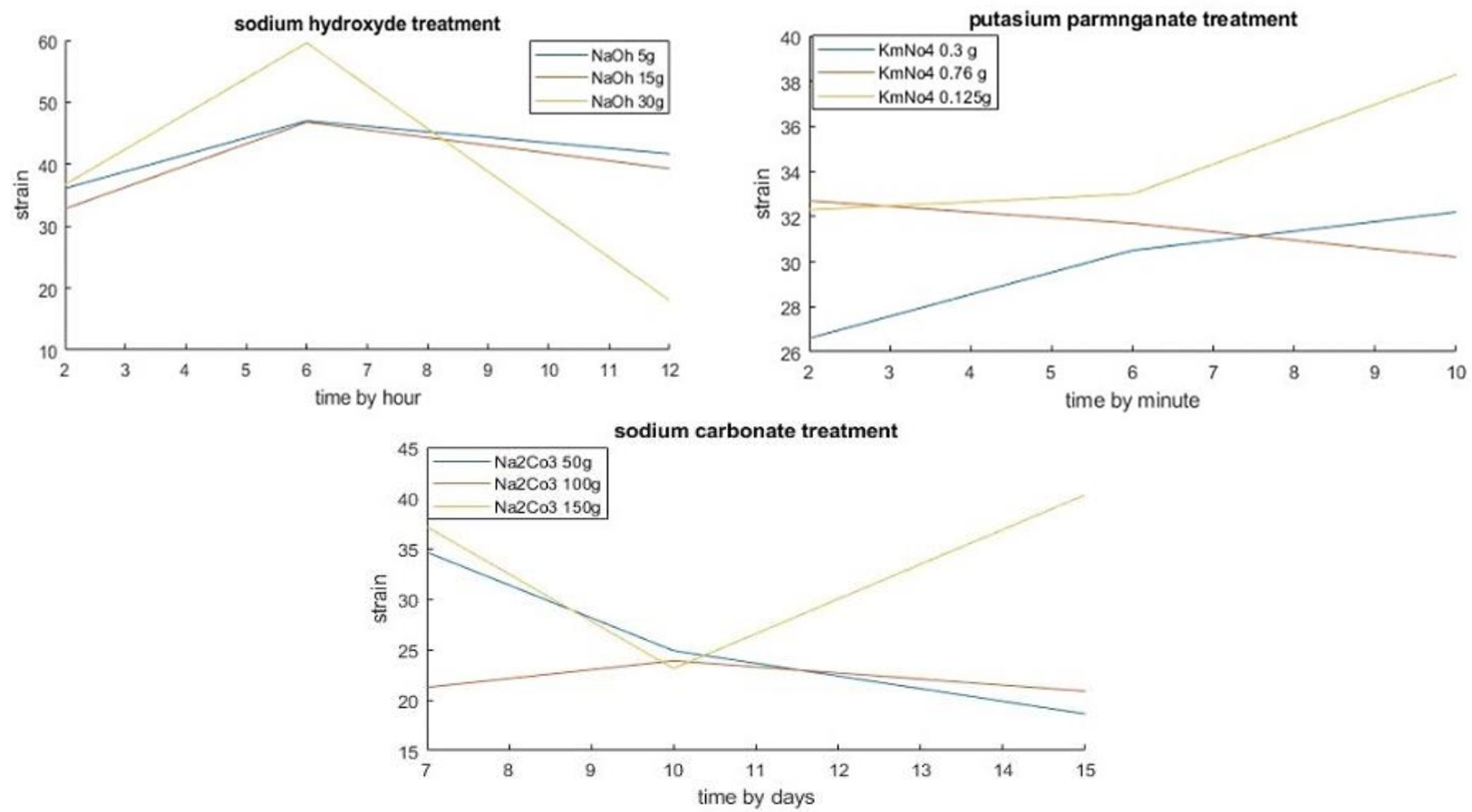

Fig. 7. Strain variation according to the chemical treatment (length of the fibers, $\mathrm{L}=80 \mathrm{~mm}$ )

In the same way, the chemical treatment with a view to improving the longitudinal modulus of elasticity (Young's modulus) of the fibers, we see from Figure 8 that it is better if $\mathrm{KMnO}_{4}(0.125 \mathrm{~g})$ is still used as the treatment medium, the Young's modulus begins to increase and improve from the second minute of treatment.

The improvement in the breaking stress of the fibers according to Figure 9, is still ensured with the use of the $\mathrm{KMnO}_{4}$ solution, as a treatment medium, a concentration of $0.75 \mathrm{~g}$ is preferable if the desired tensile strength is the order of 200 . While for a stress of order greater than 200, the use of the same solution with a $0.3 \mathrm{~g}$ concentration is essential. 

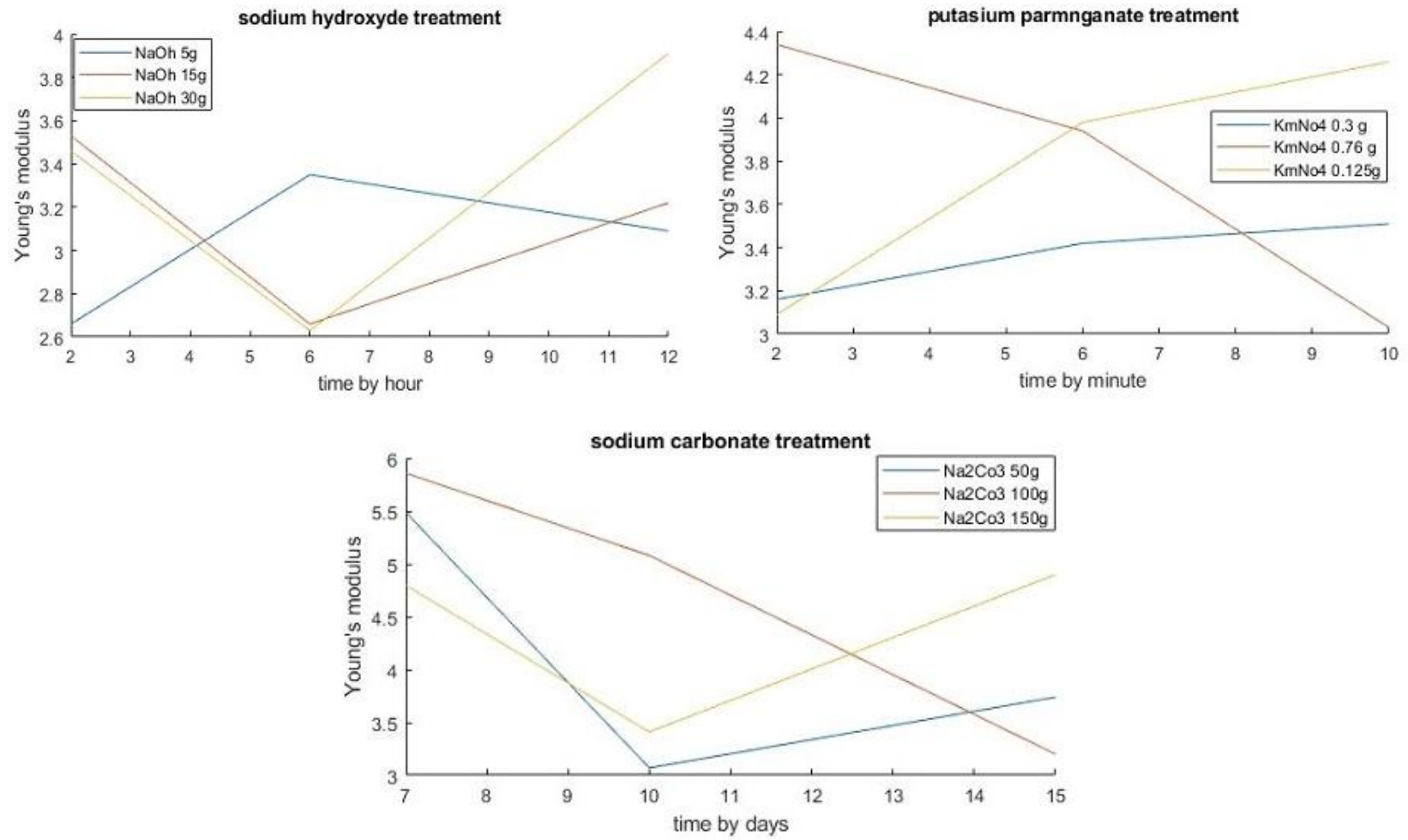

Fig. 8. Variation of the Young's modulus according to the chemical treatment
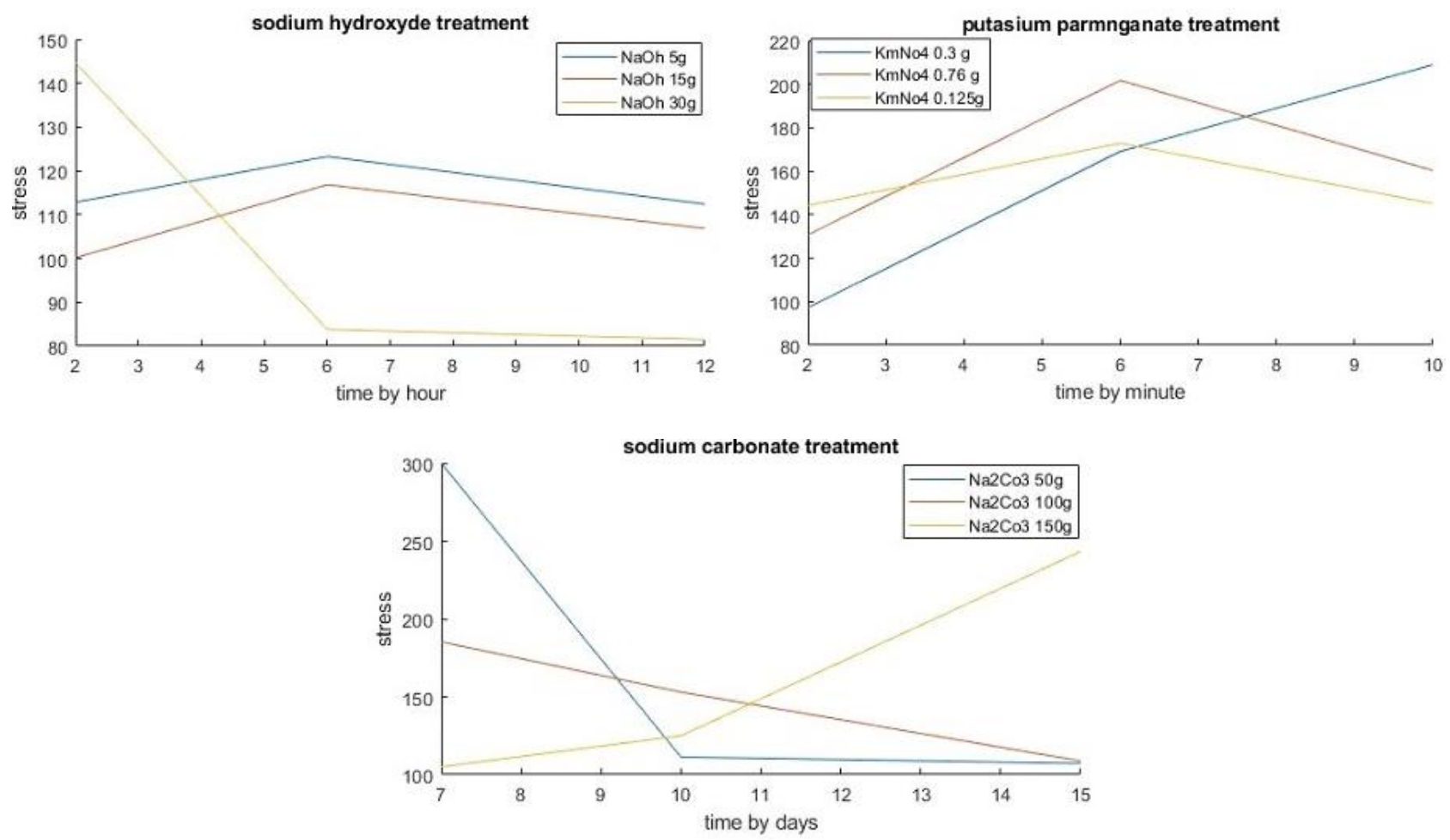

Fig. 9. Variation of the Stress of the fibers according to the chemical treatment

\section{Conclusion}

This research is a contribution to improve the mechanical characteristics of natural fibers to use as reinforcement to bio-composite materials by chemicals $\left(\mathrm{NaOH}, \mathrm{KMnO}_{4}, \mathrm{Na}_{2} \mathrm{CO}_{3}\right)$ and also to enhance the protection of the environment.

This research shows that the characteristics of natural fibers in our time are very important. 
Chemicals products play an important role in exploiting natural fibers as reinforcements of biocomposite materials.

In conclusion, the improvement of the mechanical properties of natural fibers for possible uses under more or less severe conditions is necessary, the chemical treatment of materials for searching the specific properties is also important.

For our study, we confirmed that the use of $\mathrm{KMnO}_{4}$ as a chemical solution for the improvement of the mechanical properties of natural fibers namely, the stress of rupture, the Young's modulus and the deformation stress is the best compared to other solutions $\left(\mathrm{NaOH}\right.$ and $\left.\mathrm{Na}_{2} \mathrm{CO}_{3}\right)$.

\section{References}

1. Angelloz C., Caramaro L., Laine P., Vaija J. (2005): Comportement au vieillissement de fibres textiles synthétiques composantes de sangles, élingues et cordes toronnées (Behavior on aging of synthetic textile fibers components of straps, slings and strands ropes). Rapport de recherche, Notes scientifiques et techniques de l'INRS NS 258 (in French), https://hal-lara.archives-ouvertes.fr/hal-01420183/document

2. Belaadi A. (2015): Elaboration et caractérisation des matériaux bio-composites (Development and characterization of bio-composite materials). PhD thesis, Université du 8 Mai 1945 Guelma, Faculty of Mechanical engineering, Algeria, http://dspace.univ-guelma.dz:8080/xmlui/handle/123456789/332 (in French)

3. Hulle A., Kadole P., Katkar P. (2015): Agave Americana Leaf Fibers. Fibers, ISSN 2079-6439, no. 3, p. 64-75, doi:10.3390/fib3010064, https://www.researchgate.net/publication/272386672 Agave Americana Leaf Fibers

4. Saraswat B.K., Gope P.C. (2017): Effects of Alkali Treatment on Agave Americana Fibre. International Journal of Engineering Technology, Management and Applied Sciences, ISSN 2349-4476, Vol. 5, is. 6, p. 163-172, http://www.ijetmas.com/admin/resources/project/paper/f201706111497183970.pdf

5. El Oudiani A., Msahli S., Sakli F., Drean J.-Y. (2015): Variability in Mechanical Properties of Agave Americana L. Fiber "Intra-Plant Study". Advances in Materials, ISSN 2327-2503, Vol. 4, is. 5-1, p. 15-29, doi: 10.11648/j.am.s.2015040501.13,

http://article.sciencepublishinggroup.com/html/10.11648.j.am.s.2015040501.13.html

6. Navya Geethika V., Durga Prasada Rao V. (2017): Study of Tensile Strength of Agave Americana Fibre Reinforced Hybrid Composites. Materials Today: Proceedings, ISSN 2214-7853, Vol. 4, is. 8, p. 7760-7769, ICAAMM-2016 Conference, Telangana, India, https://doi.org/10.1016/j.matpr.2017.07.111

7. Msahli S., Sakli F., Drean J.-Y. (2006): Study of textile potential of fibres extracted from Tunisian agave American $L$. AUTEX Research Journal, ISSN 1470-9589, Vol. 6, is. 1, p. 9-13, http://www.autexrj.com/cms/ zalaczone pliki/2-06-1.pdf

8. https://www.aujardin.info/plantes/agave-americana-cv-marginata.php

9. Boudjema H.L. (2016): Elaboration de matériaux composites biodégradables issus de ressources renouvelables (Development of biodegradable composite materials from renewable resources). $\mathrm{PhD}$ thesis, University of Oran 2, Algeria, https://ds.univ-oran2.dz:8443/bitstream/123456789/468/1/These.pdf (in French)

10. Cheradid Zaki (2017): Différents traitements des fibres des bio-matériaux. Master thesis. Mechanical Engineering, University of Biskra, Algeria (in French)

11. https://www.futura-sciences.com/sciences/definitions/chimie-hydroxyde-sodium-15036/

12. https://www.futura-sciences.com/sciences/definitions/chimie-permanganate-potassium-15038/

13. http://fr.wikipedia.org/wiki/Carbonate de sodium 